\title{
Dermis-Fat Graft for Contracted Socket Reconstruction in an Indigenous Black Population, Southwestern Nigeria
}

\author{
Oluyemi Fasina \\ Department of Ophthalmology, University College Hospital/University of Ibadan, Ibadan, Nigeria \\ Email: yemifash2000@yahoo.com
}

How to cite this paper: Fasina, O. (2019) Dermis-Fat Graft for Contracted Socket Reconstruction in an Indigenous Black Population, Southwestern Nigeria. Case Reports in Clinical Medicine, 8, 87-92. https://doi.org/10.4236/crcm.2019.84010

Received: March 30, 2019

Accepted: April 16, 2019

Published: April 19, 2019

Copyright (อ 2019 by author(s) and Scientific Research Publishing Inc. This work is licensed under the Creative Commons Attribution International License (CC BY 4.0).

http://creativecommons.org/licenses/by/4.0/

\section{Open Access}

\begin{abstract}
The purpose of this case series is to report the indications for dermis-fat grafting and the outcome of treatment in orbital soft tissue contraction among patients in a tertiary center. It is a retrospective, consecutive, interventional case series where all patients with orbital soft tissue contraction who had dermis-fat grafting were studied. All nine patients in our series underwent secondary dermis-fat grafting for orbital soft tissue reconstruction. The major cause for contracted socket was surgical eye removal following trauma. Eight of nine patients had no orbital implants inserted at the time of primary eye removal and eight patients have had failed orbital reconstructive procedures. Satisfactory cosmetic results were reported in all patients postoperatively. Dermis-fat grafting for contracted socket reconstruction was found to give satisfactory cosmetic results in our studied population.
\end{abstract}

\section{Keywords}

Anophthalmic Socket, Contracted Socket, Dermis-Fat Graft, Nigeria, Outcome

\section{Introduction}

Surgical eye removal procedures can result in orbital tissue shrinkage and shallow fornices with difficulty in prosthesis insertion and resultant unacceptable cosmetic appearance, thus, necessitating socket reconstruction [1]. Dermis-fat grafting for anophthalmic socket reconstruction which was introduced in 1978 by Smith and Petrelli [2], has been used in primary reconstruction of the socket after surgical eye removal procedures or, following migration or extrusion of the orbital implant [2] [3] [4]. The dermis-fat graft can restore both orbital volume and adequate fornix with minimal chances of extrusion [5]. Although there are 
reports on dermis-fat graft in orbital reconstruction in literature, to the best of the author's knowledge, none has been published in Nigeria. Hence, this case series to highlight the indications and outcome of dermis-fat grafting for orbital soft tissue reconstruction in patients managed at a tertiary health facility.

\section{Methods}

A retrospective, interventional, non-randomized case series of all patients managed at a single tertiary center, the University College Hospital, Ibadan, Nigeria, between October 2008 and September 2018 was carried out. All patients were operated by a single surgeon. The medical records of the patients were reviewed to retrieve information on the patients' socio-demographics, previous socket reconstructions, post-operative appearance and subjective satisfaction with the outcome of the procedure.

The procedures were performed under general anesthesia or local anesthesia (peribulbar block using 2\% lidocaine with 1:100,000 adrenaline and $0.5 \%$ bupivacaine mixture). The socket was prepared for the dermis-fat graft by incising the conjunctiva, and dissecting it into the fornices, following which measurement of the defect was done (Figure 1). About $30 \%$ was added to the measured defect in the harvested graft to allow for shrinkage of the graft. The grafts were taken from the lower abdomen. The donor site was infiltrated with the local anesthetic irrespective of the anesthesia employed for the procedure. An elliptical skin incision was made (Figure 2), and the epidermis was dissected off the underlying dermis using 15 number blade (Figure 3). The appropriately sized dermis with underlying fat was then harvested (Figure 4). The donor site was closed

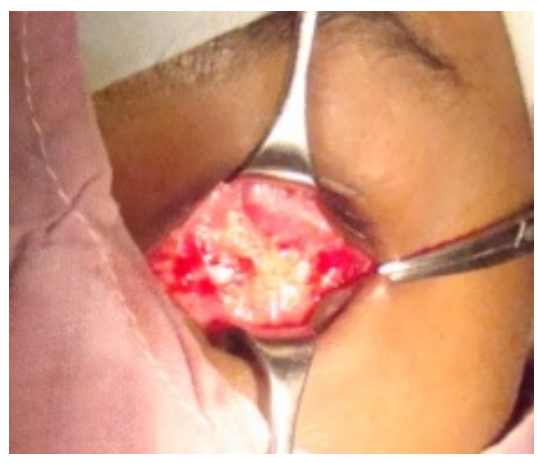

Figure 1. Clinical picture showing the recipient bed for the dermis-fat graft.

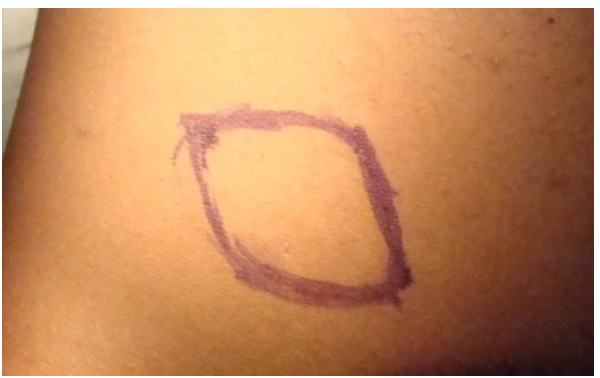

Figure 2. Clinical picture of the donor site for the dermis-fat graft in the lower abdomen. 


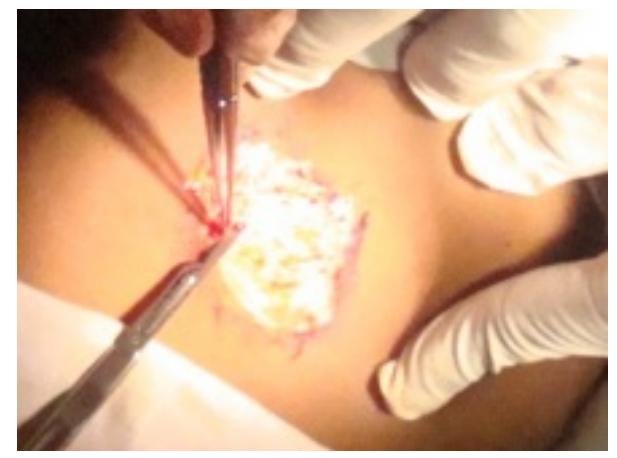

Figure 3. Clinical picture showing removal of the epidermis with 15 number blade.

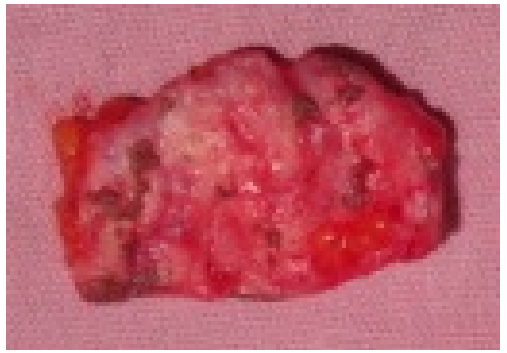

Figure 4. Clinical picture of the harvested dermis-fat graft.

in layers using 4-0 vicryl and 4-0 prolene sutures. The harvested graft was partly and appropriately defatted with scissors, placed into the socket with the dermis layer anteriorly oriented and sutured to the conjunctival edge with interrupted 6-0 vicryl suture. A plastic conformer was placed into the socket, temporary tarsorrhaphy was applied, and a light dressing of the eye was done after instilling chloramphenicol ointment. Consent was obtained from the patients and approval for the study was obtained from the Institutional Ethics Committee and the study conformed to the tenets of the Declaration of Helsinki.

\section{Results}

Nine patients, (M:F, 1:2), average age, 18.4 years (range, 1 year 8 months to 57 years) had dermis-fat grafting during the study period. Two patients were less than 2 years of age ( 1 year 8 months and 1 year 10 months) while two patients were over 50 years ( 56 years and 57 years). The demographic data are shown in the Table. Eight of nine patients have had previously failed reconstructive surgeries for contracted socket prior to the dermis-fat grafting which included oral mucosal grafting (4 patients), fornix formation suture (2 patients), and transposition flap (1 patient), while details of the procedures were not clear in one patient. All patients presented with difficulty in inserting their prosthesis due to contracted socket. The indication for the surgical removal of the eye was trauma in six cases, while three children (less than 5 years of age) had congenital buphthalmos or congenital anophthamos. These indications are shown in the Table 1. The interval between eye removal procedures in the patients and dermis-fat grafting averaged 9.2 years (range, 1 year to 28 years). Primary orbital implant 
was inserted in only one patient ( 1 year 10 month child) during the surgical eye removal procedure. There were no intra-operative complications recorded in our series, and one patient had prolonged post-operative socket infection (controlled with Guttae moxifloxacin and Guttae tobramycin). Two patients underwent additional procedures, extreme lateral permanent tarsorrhaphy, post-operatively to correct lower eyelid laxity. All patients reported marked improvement and satisfaction in their cosmetic appearance after the surgical procedure (Figure 5 and Figure 6).

\section{Discussion}

Dermis-fat grafting is one of the surgical treatment options for anophthalmic socket reconstruction and can be used in primary procedure following surgical removal of the eye or secondarily, following extrusion or migration of existing orbital implant [2] [5]. It is a free graft which receives vascularization from the recipient soft-tissue bed and has the ability for continuous growth [6]. It has a major advantage of being able to replace orbital volume as well as create adequate fornix for acceptable fitting of orbital prosthesis [2].

Primary dermis-fat grafting had been reported in previous studies [3] [5] [7], however, all the patients in our series have had primary surgical eye removal procedures from their referring health facilities and subsequently secondary dermis-fat grafting performed in our facility. Surgical eye removal procedures with primary insertion of polymethyl methacrylate implant as currently practiced in our center, presumably accounts for nil cases of contracted socket necessitating secondary dermis-fat grafting in patients managed primarily in our facility during the study period. Other advantages of using synthetic materials as primary orbital implants over dermis-fat graft include avoiding a second surgical site with the ensuing scar formation and reduction in the surgical time [8].

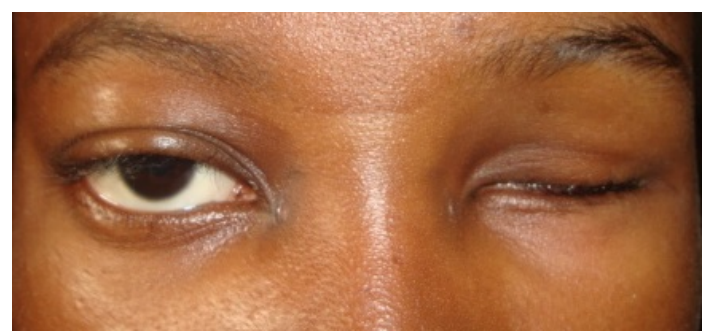

Figure 5. Pre-operative clinical picture of a patient with contracted left socket.

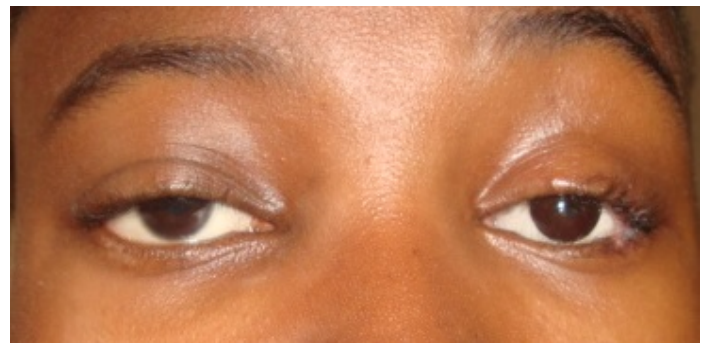

Figure 6. Post-operative clinical picture of the patient with placement of a stock prosthesis. 
Table 1. Clinical details of nine patients with orbital reconstruction using dermis-fat graft.

\begin{tabular}{|c|c|c|c|c|c|c|}
\hline & Gender & Age & Cause of anophthalmia & $\begin{array}{l}\text { Previous reconstruction/primary } \\
\text { implant placement }\end{array}$ & Anesthesia & $\begin{array}{l}\text { Outcome/further } \\
\text { procedure }\end{array}$ \\
\hline 1 & Female & 13 years & Evisceration post trauma & Nil. No implant & GA & $\begin{array}{l}\text { Satisfactory. Lateral } \\
\text { tarsorrhaphy }\end{array}$ \\
\hline 2 & Male & 36 years & Enucleation post blast injury & Oral mucosal graft. No implant & GA & Satisfactory \\
\hline 3 & Female & 1 year 10 months & Enucleation for congenital buphthalmos & Oral mucosal graft. No implant & GA & Satisfactory \\
\hline 4 & Female & 26 years & Enucleation post gunshot injury & Transposition flap. No implant & GA & $\begin{array}{l}\text { Satisfactory. Lateral } \\
\text { tarsorrhaphy }\end{array}$ \\
\hline 5 & Female & 4 years & $\begin{array}{l}\text { Enucleation for congenital } \\
\text { anophthalmos with orbital cyst }\end{array}$ & Oral mucosal graft. Had an implant & GA & Satisfactory \\
\hline 6 & Male & 57 years & $\begin{array}{l}\text { Evisceration for disfigured eyeball post } \\
\text { fist injury }\end{array}$ & $\begin{array}{l}\text { Fornix formation suture. No } \\
\text { implant }\end{array}$ & GA & Satisfactory \\
\hline 7 & Female & 1 year 8 months & $\begin{array}{l}\text { Enucleation for congenital } \\
\text { anophthalmia }\end{array}$ & Not known. No implant & GA & Satisfactory \\
\hline 8 & Female & 42 years & $\begin{array}{l}\text { Evisceration for painful blind eye post } \\
\text { trauma }\end{array}$ & Oral mucosal graft. No implant & LA & Satisfactory \\
\hline 9 & Male & 56 years & Evisceration post trauma & $\begin{array}{l}\text { Fornix formation suture. No } \\
\text { implant }\end{array}$ & GA & Satisfactory \\
\hline
\end{tabular}

$\mathrm{GA}=$ General anesthesia, $\mathrm{LA}=$ local anesthesia.

Dermis-fat grafting can be performed in all age groups including children and, two of our patients are less than 2 years of age. Dermis-fat graft serves as an ideal, dynamic orbital implant with its biocompatibility and ability to grow over time thus stimulating orbital growth [8]. This is a major advantage for its use in orbital reconstruction in children as continuous growth of the composite graft with the surrounding orbital tissue ensures sustained development of the anophthalmic socket [7] [8] [9].

Complications of dermis-fat grafting are quite common, although often minor and include graft necrosis and atrophy, granuloma formation, graft hirsutism, socket keratinization, wound dehiscence, and hematoma of the donor site [3] [8] [10]. The only complication recorded in our series was prolonged socket infection post-operatively in one patient which was treated with topical antibiotics. However, the few number of cases in the series could account for this apparent low complications recorded.

\section{Conclusion}

In conclusion, the major indication for dermis-fat grafting in our region is contracted socket following surgical removal of the eye as a result of trauma. Primary orbital implants were not inserted at time of surgery in these patients. Dermis-fat grafting gives satisfactory cosmetic results with minimal complications in our patients.

\section{Conflicts of Interest}

The author declares no conflicts of interest regarding the publication of this paper. 


\section{References}

[1] Babar, T.F., Hussain, M. and Zaman, M. (2009) Clinico-Pathologic Study of 70 Enucleations. Journal of Pakistan Medical Association, 59, 612-614.

[2] Smith, B. and Petrelli, R. (1978) Dermis-Fat Graft as a Movable Implant within the Muscle Cone. American Journal of Ophthalmology, 85, 62-66. https://doi.org/10.1016/S0002-9394(14)76666-8

[3] Smith, B., Bosniak, S., Nesi, F. and Lisman, R. (1983) Dermis-Fat Orbital Implantation: 118 Cases. Ophthalmic Surgery, 14, 941-943.

[4] Jordan, D.R., Klapper, S.R., Gilberg, S.M., et al. (2010) The Bioceramic Implant: Evaluation of Implant Exposures in 419 Implants. Ophthalmic Plastic \& Reconstructive Surgery, 26, 80-82. https://doi.org/10.1097/IOP.0b013e3181b80c30

[5] Aryasit, O. and Preechawai, P. (2015) Indications and Results in Anophthalmic Socket Reconstruction Using Dermis-Fat Graft. Clinical Ophthalmology, 9, 795-799. https://doi.org/10.2147/OPTH.S77948

[6] Gupta, H., Nair, D., Moiyadi, A. and Pai, P. (2017) Dermis Fat Graft for Pediatric Exenteration-Challenging but Rewarding. Saudi Journal of Ophthalmology, 31, 169 172. https://doi.org/10.1016/j.sjopt.2017.04.011

[7] Tarantini, A. and Hintschich, C. (2008) Primary Dermis-Fat Grafting in Children. Orbit, 27, 363-369. https://doi.org/10.1080/01676830802345125

[8] Bernardino, C.R. (2010) Congenital Anophthalmia: A Review of Dealing with Volume. Middle East African Journal of Ophthalmology, 17, 156-160. https://doi.org/10.4103/0974-9233.63082

[9] Al-Mujaini, A., Ganesh, A. and Al-Zuhaibi, S. (2007) Autogenous Dermis-Fat Orbital Implant for Anophthalmic Socket. Sultan Qaboos University Medical Journal, 7, 145-148.

[10] Bosniak, S.L. (1990) Complications of Dermis-Fat Orbital Implantation. Advances in Ophthalmic Plastic and Reconstructive Surgery, 8, 170-181. 